\title{
A novel multi-epitope recombined protein for diagnosis of human brucellosis
}

\author{
Dehui Yin ${ }^{1 \dagger}$, Li Li ${ }^{1 \dagger}$, Xiuling Song ${ }^{1}$, Han Li ${ }^{1,2}$, Juan Wang ${ }^{1}$, Wen Ju' ${ }^{1}$, Xiaofeng Qu', Dandan Song ${ }^{1}$, Yushen Liu',

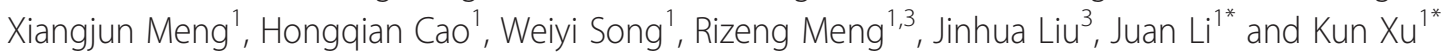

\begin{abstract}
Background: In epidemic regions of the world, brucellosis is a reemerging zoonosis with minimal mortality but is a serious public hygiene problem. Currently, there are various methods for brucellosis diagnosis, however few of them are available to be used to diagnose, especially for serious cross-reaction with other bacteria.

Method: To overcome this disadvantage, we explored a novel multi-epitope recombinant protein as human brucellosis diagnostic antigen. We established an indirect enzyme-linked immunosorbent assay (ELISA) based on this recombinant protein. 248 sera obtained from three different groups including patients with brucellosis (146 samples), non-brucellosis patients (82 samples), and healthy individuals (20 samples) were tested by indirect ELISA. To evaluate the assay, a receiver-operating characteristic $(\mathrm{ROC})$ analysis and immunoblotting were carried out using these characterized serum samples.
\end{abstract}

Results: For this test, the area under the ROC curve was 0.9409 (95 \% confidence interval, 0.9108 to 0.9709), and a sensitivity of $88.89 \%$ and a specificity of $85.54 \%$ was given with a cutoff value of 0.3865 from this ROC analysis. The Western blot results indicate that it is feasible to differentiate human brucellosis and non-brucellosis with the newly established method based on this recombinant protein.

Conclusion: Our results obtained high diagnostic accuracy of the ELISA assay which encourage the use of this novel recombinant protein as diagnostic antigen to implement serological diagnosis of brucellosis.

Keywords: Brucellosis, Diagnosis, Recombinant protein

\section{Background}

Brucella spp. are Gram-negative, facultative, intracellular bacterial pathogens that cause brucellosis, an infectious disease affecting animals and humans [1]. Based on the difference in pathogenicity and host preference, three main human brucellosis pathogens, B. melitensis, B. abortus, and B. suis (whose preferred natural host animals are sheep and goats, cattle, and swine, respectively), can infect humans, involving any organ or system of the body, and lead to serious complications with important public health issues [2]. The infection is primarily transmitted by consumption of unpasteurized dairy products, direct contact with infected animals, handling of cultures or clinical specimens. The disease remains endemic in many regions

\footnotetext{
* Correspondence: li_juan@jlu.edu.cn; xukun@jlu.edu.cn

${ }^{\dagger}$ Equal contributors

'Department of Health Laboratory, School of Public Health, Jilin University,

Changchun, China

Full list of author information is available at the end of the article
}

of the world, including Latin America, the Middle East, Africa, Asia, and the Mediterranean basin, affecting approximately 500,000 people annually around the world [3]. As the largest developing country in the world, the incidence of human brucellosis has rapidly increased in China since 1995 [4]. According to data from the Chinese Center for Disease Control and Prevention (CDC), more than 57,000 human cases were identified in 2014 (http:// www.nhfpc.gov.cn/jkj/s3578/ 201502/847c041a3bac4c3e8 44f17309be0cabd.shtml). According to the previous study, brucellosis is mainly distributed in some of the northern provinces of China, accounted for $>90 \%$ of the reported cases. Jilin province has the fourth highest incidence, with the annual incidence ranging from 50 to 100 per 1000,000 [5].

Because of a deficiency of clinical pathognomonic symptoms, a prompt and accurate diagnosis is important. Current methods used for identification of brucellosis 
include traditional culture-, immunological-, and molecularbased methods, which usually follow a bacterial enrichment step. Blood culture, which was considered the golden standard method, provides the definitive diagnosis of brucellosis but may not provide a positive result for all patients [6]; it presents several other drawbacks, such as being time-consuming and dangerous for personnel, and few laboratories have suitable culture conditions [7]. Although polymerase chain reaction (PCR) and real-time PCR assays are very promising, infrastructure, equipment, and expertise are lacking in developing countries [8].Therefore, serological tests, such as the enzyme-linked immunosorbent assay (ELISA) and standard tube agglutination test (SAT), have become the most useful tools for diagnosis of brucellosis. In particular, ELISA can provide higher sensitivity and specificity compared with SAT [9]. The crucial part of ELISAs is a sensitive and specific diagnostic antigen. Several immunogenic Brucella spp. surface-exposed outer membrane proteins (OMPs), such as OMP16 [10], OMP25 [11], OMP2b [12], and OMP31 [13], and periplasmic protein 26 (BP26) [14] have been previously identified, which indicates these immunoreactive proteins are potential candidates of diagnostic antigens for ELISAs.

Currently, in endemic areas, many countries have developed control measures for eradicating the disease in livestock animals. Vaccination is probably the most common measure for controlling brucellosis; live attenuated vaccines were used. Unfortunately, because the vaccines could cause animal abortion, infertility, weak offspring, and other shortcomings their application was blocked [15]. In order to overcome these disadvantages, researchers are trying to develop new vaccines, and recombination vaccines were produced [16]. Prediction of antigenic epitopes on protein surfaces is important for vaccine design. Most existing epitope prediction methods focus on protein sequences to predict continuous epitopes linear in sequence. These prediction methods are based upon the amino acid properties, including immunoinformatic analysis and prediction of B-cell epitopes, such as hydrophilicity [17], surface accessibility [18], secondary structure [19], flexibility [20], ABCPred [21], COBEPro [22], and BepiPred [23]. With the development of these bioinformatics methods, they provide more cost-effective approaches for seeking Brucella vaccines and brucellosis diagnostic antigens.

For diagnose specificity, monoclonal antibodies are the best option, but a monoclonal antibody can recognize only one unique epitope. The preparation of monoclonal antibodies is time-consuming and laborious, and whether monoclonal antibodies can be prepared in large batches depends on the luck component. In the present work, we used bioinformatic methods for B-cell epitope prediction to predict B-cell epitopes of OMP16, OMP2b, OMP31, and BP26; based on these predicted B-cell epitopes, we designed a novel recombinant protein for serological diagnostic of brucellosis. We expressed and purified this recombinant protein and finally evaluated it for its diagnostic utility with ELISA and Western blotting. Our design can avoid the shortcomings of monoclonal antibodies.

\section{Methods \\ Computer modeling prediction of epitopes}

Amino acid sequences of OMP16, OMP2b, OMP31, and BP26 were obtained from the National Center for Biotechnology Information (NCBI) Database at http:// www.ncbi.nlm.nih.gov. To ensure the accuracy of prediction, three different epitope prediction software programs based on the protein sequences were used to predict the most immunogenic linear B-cell epitopes: Bepipred (http://www.cbs.dtu.dk/services/Bepipred/), ABCpred (http://www.imtech.res.in/raghava/abcpred/), and COBEpro (http://scratch.proteomics.ics.uci.edu/). To find the presence or absence of predicted epitopes across species, the BLASTP was performed.

\section{Construction, expression, and purification of recombinant proteins}

First, the predicted B-cell epitopes were selected to construct the recombinant outer membrane protein(rOmp). Then adjacent epitopes were joined together by the linker "GGGS." The recombinant protein gene was synthesized by Sangon Biotech (Shanghai, China), which had a sixHis-tag-encoding sequence at the $3^{\prime}$ end, by using codon optimized to permit expression in Escherichia coli. The synthetic gene was inserted in the bacterial expression vector pET-28b (+) to generate the plasmid pET28b (+); then the recombinant plasmid was transformed into $E$. coli BL21 (DE3) cells to induce recombinant protein expression with $0.2 \mathrm{mM}$ isopropyl- $\beta$-D-thiogalactoside (IPTG).

The transformed $E$. coli BL21 cells were grown in a shaker at $220 \mathrm{rpm}$ and $37^{\circ} \mathrm{C}$, inoculated into $4 \mathrm{~L}$ of LuriaBertani (LB, containing $30 \mu \mathrm{g} / \mathrm{ml}$ kanamycin) at a dilution of 1:100. When the optical density at $600 \mathrm{~nm}$ (OD600) of the culture reached approximately 0.6 , the culture was induced by $0.2 \mathrm{mM}$ IPTG. Induction was grown overnight, and cells were collected by centrifugation. Aliquots of the induced and noninduced cell cultures were analyzed by SDS-PAGE prior to purification.

The collected cells were dissolved with a lysis buffer (7 M guanidine hydrochloride, $50 \mathrm{mM}$ Tris, $300 \mathrm{mM}$ $\mathrm{NaCl}, 0.1$ \% Triton X-100, DNase I, RNase, lysozyme, $\mathrm{pH}=8.0)$ and then homogenized by sonication on ice (power $400 \mathrm{~W}, 20 \mathrm{~min}$, ultrasonic $3 \mathrm{~S}$, pause $5 \mathrm{~S}$ for a loop). The lysate was clarified by centrifugation at $10,000 \times \mathrm{g}$ for $20 \mathrm{~min}$ at $4{ }^{\circ} \mathrm{C}$; then the supernatant was collected for purification. The supernatant was gently shaken with $5 \mathrm{ml}$ of Ni-nitrilotriacetic acid (NTA). The column was preequilibrated with a binding buffer $(7 \mathrm{M}$ Gua-Hcl, $50 \mathrm{mM}$ 
Tris, $300 \mathrm{mM} \mathrm{NaCl}, \mathrm{pH}=8.0$ ). After the flow-through was collected, the column was washed extensively with wash buffer (8 M urea, $50 \mathrm{mM}$ Tris, $300 \mathrm{mM} \mathrm{NaCl}, 10 / 20$ / $50 \mathrm{mM}$ imidazole, $\mathrm{pH}=8.0)$ and elution buffer eluent $(8 \mathrm{M}$ urea, $50 \mathrm{mM}$ Tris, $300 \mathrm{mM} \mathrm{NaCl}, 500 \mathrm{mM}$ imidazole, $\mathrm{pH}$ =8.0); the eluent was collected.

The purified rOmp protein was run on $12 \%$ SDSPAGE gel and transferred to a polyvinylidene fluoride (PVDF) membrane in a trans-blot system. After the transfer, the membrane was blocked with $5 \%$ skim milk at $4{ }^{\circ} \mathrm{C}$ overnight, and then washed three times with phosphate-buffered saline containing $0.05 \%$ Tween 20 (PBST) and incubated with a rabbit anti-His-tag polyclonal antibody (at 1:1000 dilution) for $1 \mathrm{~h}$ at $37^{\circ} \mathrm{C}$. The membrane was washed three times again, and incubated with horseradish peroxidase (HRP)-conjugated goat antirabbit immunoglobulin (Ig)G antibodies at 1:10,000 dilutions for $1 \mathrm{~h}$ at $37^{\circ} \mathrm{C}$. After washing again, the protein bands were incubated in diaminobenzidine (DAB) substrate solution for $15 \mathrm{~min}$ at $37^{\circ} \mathrm{C}$.

Concentrations of purified proteins were measured by non-interference protein assay kit SK3071 (Sangon Biotech,Shanghai, China), according to the instructions supplied by the kit manufacturer.

\section{Samples}

248 serum samples from three different clinical groups were provided by Plague and Brucellosis Prevention and Control Base, Chinese CDC, Baicheng, Jilin, China:

(1) 146 serum brucellosis samples of culture-positive, which were serologically positive by plate agglutination test (PAT) and standard tube agglutination test (SAT) as standard methods for diagnosis of brucellosis.

(2) 82 serum samples of non-brucellosis infected other bacteria, including E. coli (5 serum samples), Staphylococcus (10 serum samples), Proteus mirabilis (2 serum samples), Enterobacter cloacae (2 serum samples), Streptococcus salivarius (2 serum samples), Streptococcus viridans (2 serum samples), and Klebsiella pneumoniae (6 serum samples), Salmonella enteritidis (1 serum samples), and fever of unknown origin (62 serum samples).

(3) 20 serum samples of healthy individuals were collected. The samples of non-brucellosis patients and healthy donors were verified as non-brucellosis by PAT and SAT.

Venous blood $(5 \mathrm{ml})$ was collected from the patients and healthy individuals; supernatants were harvested after centrifugation at $1,200 \mathrm{~g}$ for $10 \mathrm{~min}$ and stored at $-70{ }^{\circ} \mathrm{C}$ until assayed. A titer of 1:100 and higher was considered as a suspected positive result for brucellosis by PAT or
SAT, and blood culture was subsequently used for verification.

\section{IELISA and Western blot analysis}

Ninety-six-well microtiter plates (Corning, USA) were coated with $1 \mu \mathrm{g}$ per well of the recombinant protein in coating buffer (0.01 M PBS, pH 7.4) and incubated overnight at $4{ }^{\circ} \mathrm{C}$. After three washes with PBST, the plates were blocked with $1 \%$ bovine serum albumin (BSA, Sigma, USA) for $2 \mathrm{~h}$ at $37{ }^{\circ} \mathrm{C}$ and then incubated with serum 1:400 in PBST containing $1 \%$ BSA for $1 \mathrm{~h}$ at $37^{\circ} \mathrm{C}$. After a washing step, a 1:10,000 diluted HRP-goat anti-human IgG secondary antibody (Invitrogen, USA) was added and incubated at $37{ }^{\circ} \mathrm{C}$ for $1 \mathrm{~h}$. The plates were washed, and then $100 \mu \mathrm{l}$ of the TMB substrate solution was added to each well. Reactions were left to react for 15 minutes at room temperature in a dark place. Finally, $50 \mu \mathrm{l}$ of the stop solution (2 M H2SO4) was added to each well. ODs were measured at $450 \mathrm{~nm}$ using an ELISA plate reader (BioTek, USA). Positive, negative, and blank (PBS) samples were tested in triplicate, and the experiment was repeated three times. All the samples were processed simultaneously.

Meanwhile, we used the antigen of SAT (the whole bacteria antigen were supplied by Plague and Brucellosis Prevention and Control Base) to evaluate the effectiveness of our fusion protein as a diagnostic antigen for brucellosis by IELISA.

Western blotting was performed partially as described above. After recombinant proteins were transferred onto the PVDF membrane, the membranes were blocked in TBST containing $5 \%$ skim milk overnight at $4{ }^{\circ} \mathrm{C}$. Then the membranes were incubated with human serum at 1:100 dilution for $2 \mathrm{~h}$ at room temperature. After a washing step with TBST, the membranes were incubated with a 1:10,000 HRP-conjugated goat anti-human IgG secondary antibody for $1 \mathrm{~h}$ at room temperature (RT). After three washes in TBST, protein detection was visualized with the BeyoECL Plus Kit (Beyotime, China), following the manufacturer's instructions, and exposed to X-ray film. Each band was analyzed using a Gel Image System (Tanon, China).

\section{Statistical analysis}

Dotplot and receiver-operating characteristic (ROC) were performed using the GraphPad Prism version 6.05 for Windows.

\section{Results}

\section{Computer modeling prediction of epitopes}

The Accession Numbers of OMP16, OMP2b, OMP31, and BP26 were obtained from NCBIDatabase(Additional file 1: Table S3). To improve the accuracy of B-cell epitope prediction, three different epitope-prediction software programs (ABCPred, BepiPred, and COBEPro) were used to 
predict the most immunogenic linear B-cell epitopes of the fusion protein. We choose the 15 overlapping epitopes that were predicted by the three methods as B-cell epitope candidates (see Table 1), and the results of BLASTP indicated these epitopes are highly conserved in Brucella.

\section{Recombinant protein identification}

To avoid emerging new epitopes, we separated each predicted epitope by a linker (Fig. 1). By optimizing codons for E. coli expression, a resultant 1338-bp gene was synthesized by Sangon Biotech. Then we inserted the synthetic gene in the bacterial expression vector pET-28b and transformed it into E. coli BL21 (DE3) cells. Then, the induced cells were sonicated and analyzed by SDS-PAGE. A specific band representing the recombinant product was obtained (Fig. 2a). Ni-NTA affinity purification was used, and the purified products were analyzed by SDS-PAGE (Fig. $2 \mathrm{~b}$ and c). Starting from $1 \mathrm{~g}$ of the induced cell pellet, we obtained $1 \mathrm{ml}$ of rOmp protein solution with a concentration of $1.2 \mathrm{mg} / \mathrm{ml}$, as measured with a non-interference protein assay kit (SK3071, Sangon Biotech).

\section{IELISA}

To evaluate the assay, 248 serum samples including brucellosis (146 samples), non-brucellosis patients (82 samples) and healthy individuals (20 samples) were tested by indirect ELISA and Western blotting. A dotplot diagram outlined the OD values of these samples (Fig. 3a). A ROC analysis was performed to evaluate the optimize sensitivity and specificity (Fig. 3b). Based on the ROC analysis, AUC for this test was 0.9409 (95\% confidence

\begin{tabular}{|c|c|c|}
\hline Protein & $\begin{array}{l}\text { Start-end } \\
\text { position }\end{array}$ & Sequence \\
\hline \multirow[t]{3}{*}{ BP26 } & $87-124$ & KKAGIEDRDLQTGGINIQPIYVYPDDKNNLKEPTITGY \\
\hline & $151-170$ & GVNQGGDLNL VNDNPSAVIN \\
\hline & $223-245$ & AAAPDNSV PIAAGENSYNVSVNV \\
\hline \multirow[t]{4}{*}{ OMP31 } & $24-40$ & VSEPSAP TAAPVDTFSW \\
\hline & $48-83$ & NAGYAGGKFKHPFSSFDKEDNEQVSGSLDVTAGGFV \\
\hline & $109-129$ & SS VTGSISAGAS GLEGKAETK \\
\hline & $168-225$ & $\begin{array}{l}\text { GDD ASALHTWSD KTKAGWTLGAGA } \\
\text { EYAINNNWTLKSEYLYTDLGKRNLVDVDNSFLES }\end{array}$ \\
\hline \multirow[t]{2}{*}{ OMP16 } & $90-106$ & Q YSITIEGHAD ERGTRE \\
\hline & $124-146$ & ASRGVPT NRMRTISYGN ERPVAV \\
\hline \multirow[t]{6}{*}{ OMP2b } & $66-84$ & DVKGG DDVYSGTDRN GWDK \\
\hline & $194-210$ & ALEQGGD NDGGYTGTTN \\
\hline & $242-282$ & $\begin{array}{l}\text { VIEEWAAKVRGDVNITDQFSVWLQGAYSSAATPDQN } \\
\text { YGQWG }\end{array}$ \\
\hline & $268-286$ & YSS AATPDQNYGQ WGGDWA \\
\hline & $306-316$ & FNLQAAHDDW GKTAVTAN \\
\hline & $328-354$ & TVT PEVSYTKFGG EWKDTVAEDN AWGG \\
\hline
\end{tabular}

interval (CI), 0.9108 to 0.9709$)$. In addition, a diagnostic sensitivity of $88.89 \%$ (95\% CI, 82.06 to 93.79$)$ and a specificity of $85.54 \%$ (95\% CI, 76.11 to 92.30 ) was obtained from a optimum cutoff value(0.3865). With this cutoff value, 135 of 146 brucellosis cases were diagnosed correctly as positive, and only nine negative cases were diagnosed incorrectly as positive; all of the healthy individuals can be diagnosed correctly.

Furthermore, we used the antigen of SAT to diagnose brucellosis in IELISA, which was in parallel with the fusion protein, a dotplot diagram (Fig. 3c), and ROC curve (Fig. 3d). Based on same analysis, the AUC for the test was 0.8981 (95\% CI, 0.8455 to 0.9508 ), a diagnostic sensitivity of $86.99 \%$ (95\% CI, 80.43 to 91.98 )and a specificity of $82.05 \%$ (95\% CI, 66.46 to 92.46) was obtained from a optimum cutoff value(0.5730). However, with the cutoff value, 127 of 146 brucellosis cases were diagnosed correctly, and 20 negative cases were diagnosed incorrectly, including seven healthy individuals diagnosed as positive. We also have a cross-table with absolute numbers of positive and negative samples with these cutoff values (Table 2).

The results of ELISA indicate that it is possible with this assay to clearly discriminate between brucellosis and non-brucellosis cases. Compared with the whole bacterial antigen, rOMP has a weaker cross-reaction (Additional file 2: Fig. S1).To further investigate isotypespecific reactivity, IgM, IgG, and $\operatorname{Ig}(\mathrm{M}+\mathrm{G})$ ELISA tests were performed. We found that the $\operatorname{IgG}$ and $\operatorname{Ig}(M+G)$ had similar results, but only a few brucellosis samples were weakly IgM isotype positive. Compared with the antigen of SAT, 45 brucellosis samples were IgM isotype positive (Additional file 3: Table S2).

Additionally, the western blotting result indicates that the antibody could specificity binding to the recombinant protein of predicted B-cell epitopes.

\section{Discussion}

B-cell epitopes are the sites of molecules that are recognized by antibodies of the immune system. Bioinformatics is used for many purposes, especially for vaccine design and diagnostic tests. These prediction methods are based upon the properties of 20 amino acids, including immunoinformatic analysis and prediction of B-cell epitopes, such as hydrophilicity [17], surface accessibility [18], $\beta$-turn [19], and flexibility [20]. However, using bioinformatic tools to predict immunogenic B-cell epitopes remains a vital and challenging task because their rate of successful prediction is not very high. To avoid the drawbacks, three different epitope prediction software programs (ABCPred, BepiPred, and COBEPro) were used to predict the most immunogenic linear B-cell epitopes in this study. 


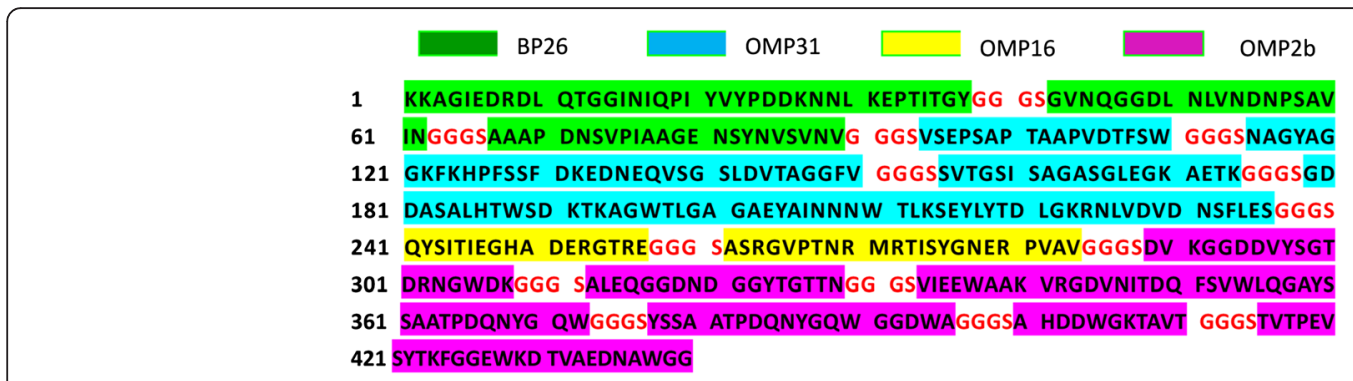

Fig. 1 Amino acid sequence of the recombinant protein in FAST format: "GGGS" is the linker

In the early 1980s and 1990s, the major outer proteins of Brucella spp. were identified and characterized as potential immunogenic and protective antigens. In recent studies, several OMPs had been demonstrated to be highly immunoreactive; these include BP26, OMP16, OMP31, OMP2b, and OMP25. In our study, we chose four OMPs (BP26, OMP16, OMP31, and OMP2b), which exist in almost all Brucella spp. We did not use OMP25 because it is present mainly in B. abortus. We used ABCPred, BepiPred, and COBEPro to predict the most immunogenic linear B-cell epitopes in the four selected OMPs. To avoid inaccuracies, we selected 15 overlapping epitopes that were predicted by all three methods.

It is reported that laboratory testing and diagnosis of brucellosis is critical for patient management [24]. Currently, numerous available diagnostic methods are difficult to perform in developing countries with poor resources, especially in endemic regions. IELISA is the best choice for diagnosing brucellosis, especially when other tests are limited. It can reveal total and individual specific immunoglobulins (IgG, IgM, IgA) rapidly (within $6 \mathrm{~h}$ ) with high sensitivity and specificity [25].
In our present study, we designed a novel antigen to detect antibodies against Brucella spp. using an indirect ELISA assay. The assay was assessed by using a series of serum samples obtained from brucellosis, non-brucellosis and healthy individuals. The sample characteristics are described in Additional file 4: Table S1. All the samples are from Baicheng city, which has a high incidence of brucellosis in China. In this region, almost all farmers breed livestock, which accounts for significant morbidity of brucellosis.

To validate the assay, an immunoblot and ROC analysis were performed. The result of AUC was 0.9409, indicating our assay has high accuracy for human brucellosis diagnose by contrast with global summary statistics of diagnostic accuracy of AUC. Our method could distinguish highly accurate $(0.9<\mathrm{AUC}<1)$ [26]. Because brucellosis patients often have gastrointestinal symptoms and fever, we chose patients with other bacterial infections as a portion of the controls, such as E. coli, Staphylococcus, Salmonella enteritidis, and fever of unknown origin. These patients are likely to be misdiagnosed. The Western blot results indicate that the newly established method based

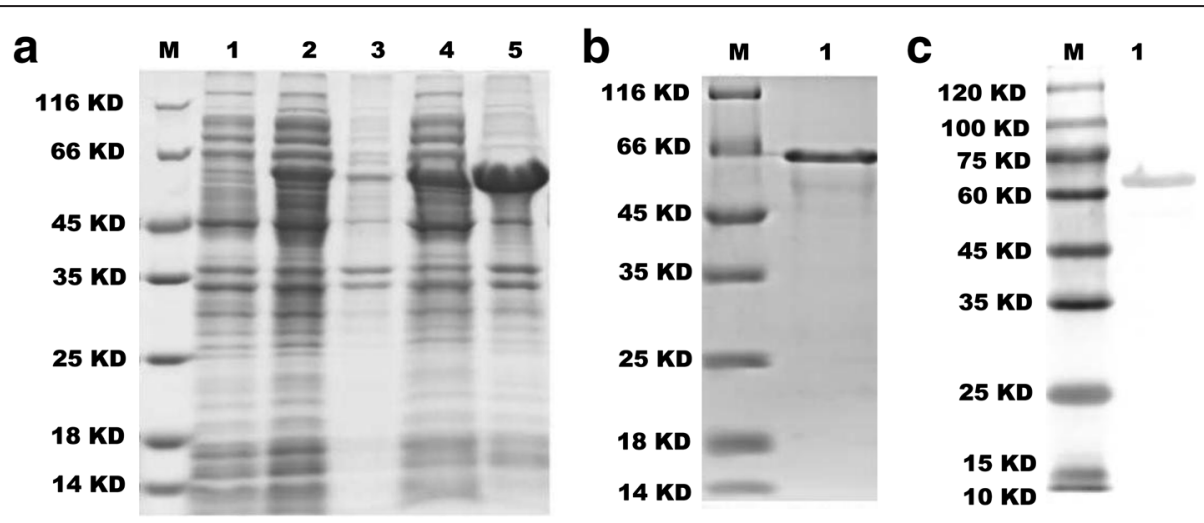

Fig. 2 Preparation and identification of recombinant protein. a SDS-PAGE of OMP-induced expression with 0.2 mM IPTG for different times (M, marker; Lane 1, uninduced cells; Lane 2, supernatant of IPTG-induced cells for 2 h; Lane 3, deposition of IPTG-induced cells for 2 h; Lane 4 , supernatant of IPTG-induced cells for 4 h; Lane 5, deposition of IPTG-induced cells for 4 h). b SDS-PAGE of OMP purification (M, marker; Lane 1, purified recombinant protein.). $\mathbf{c}$ Western blotting analysis of the purified recombinant protein using the anti-His-tag rabbit anti-His-tag polyclonal antibody (M, marker; Lane 1, purified recombinant protein) 

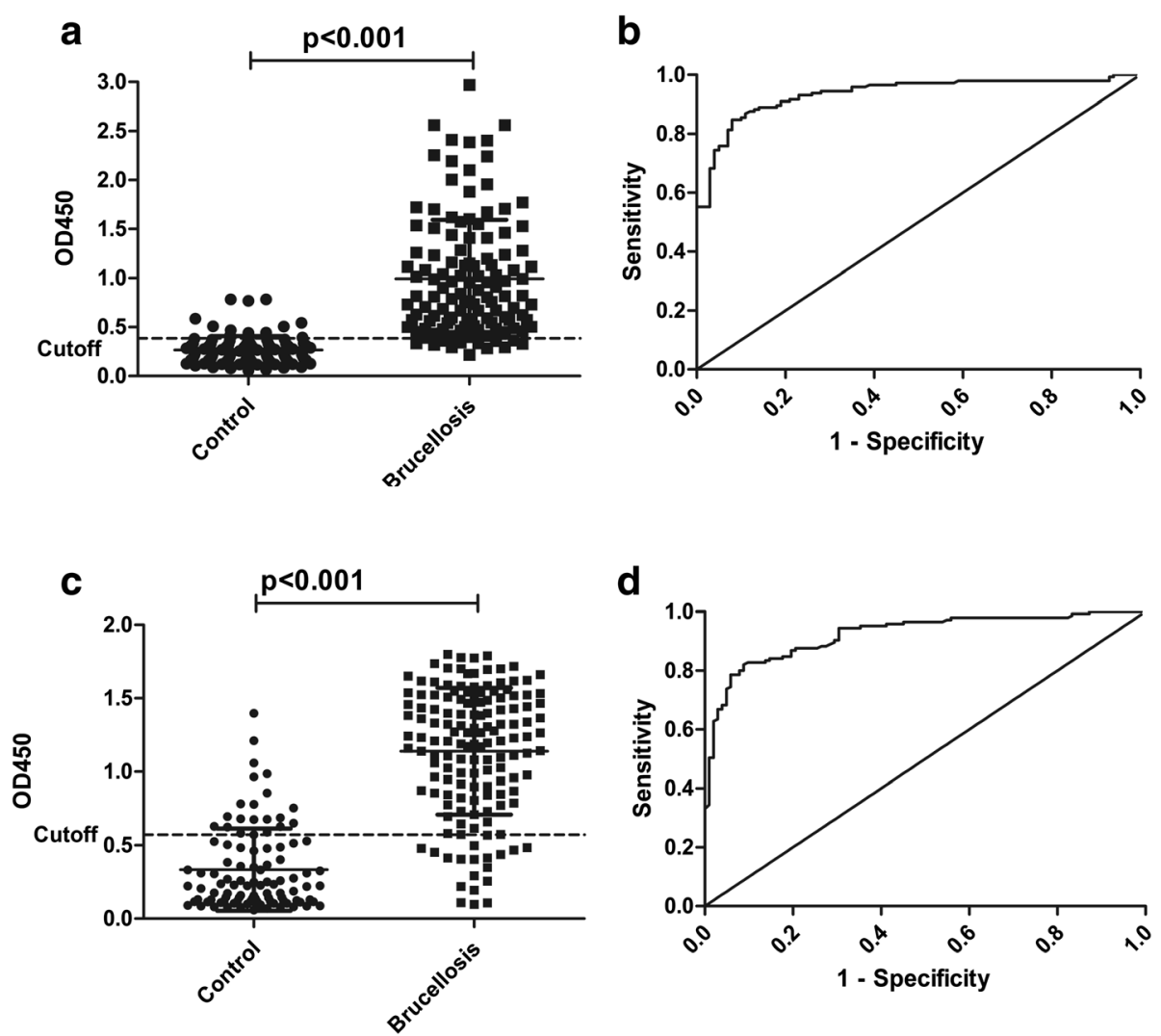

Fig. 3 IELISA analysis of serum samples. The analysis was performed considering positive control serum samples with culture-confirmed/serologically positive brucellosis (146 sera) and negative control sera from patients with other diseases and healthy individuals (102 sera). a Dotplot of the rOMP IELISA assay. $\mathbf{b}$ ROC analysis of rOMP IELISA assay results. $\mathbf{c}$ Dotplot of the SAT antigen IELISA assay results. $\mathbf{d}$ ROC analysis of SAT antigen IELISA assay results

on this recombinant protein is feasible to differentiate human brucellosis and non-brucellosis infections.

However, ELISA methods that detect IgG are sensitive but have low specificity. Measurement of IgM levels has lower sensitivity than IgG but is more specific [27]. In this case, this recombinant protein has low sensitivity to diagnose brucellosis in acute infection. The other, because of the confirmation in brucellosis reports of China, and indiscriminate therapeutic regimen, the diagnosis of brucellosis often do not distinguish Brucella species. We did not obtain any information of diagnostic value for different Brucella species infection. However, a previous study has

Table 2 Positive predictive value and negative predictive value of different cutoff values

\begin{tabular}{|c|c|c|c|c|c|c|}
\hline \multirow[t]{2}{*}{ Cutoff value } & \multicolumn{2}{|c|}{ Positive } & \multicolumn{2}{|c|}{ Negative } & \multirow[t]{2}{*}{ PPV (\%) } & \multirow[t]{2}{*}{ NPV (\%) } \\
\hline & $\mathrm{TP}$ & $\mathrm{FN}$ & $\mathrm{TN}$ & $\mathrm{FP}$ & & \\
\hline$\geq 0.3865^{a}$ & 135 & 11 & 93 & 9 & 93.75 & 89.42 \\
\hline$\geq 0.5730^{b}$ & 127 & 19 & 82 & 20 & 80.89 & 81.19 \\
\hline
\end{tabular}

TP, true positives; TN, true negatives; FP, false positives; FN, false negatives; PPV, positive predictive value $(T P / T P+F P) \times 100$; NPV, negative predictive value $(\mathrm{TN} / \mathrm{TN}+\mathrm{FN}) \times 100$

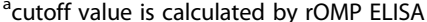

${ }^{b}$ cutoff value is calculated by antigen of SAT ELISA confirmed that $B$. melitensis is the most prominent species causing human brucellosis in China, accounting for more than $80 \%$ of the cases [28].

\section{Conclusion}

Herein, we validated the newly established IELISA assay with a high diagnostic accuracy of human brucellosis. In our study, a predicted recombinant protein from four major OMPs of Brucella was expressed for the first time and has been validated to diagnose human brucellosis. However, to fully evaluate the recombinant protein for diagnosis, further research will be necessitated for diagnostics of brucellosis caused by different Brucella spp. strains.

In addition,this recombinant protein based assay can be desiged and established for other infectious diseases diagnosis.

\section{Consent for publication \\ Not applicable.}

Ethics approval and consent to participate

The serum samples used in this study were obtained for laboratory analysis. Written informed consent for sample 
analysis was obtained from the patients. This study was approved by the Institutional Research Ethics Committee of Medicine, the School of Public Health, Jilin University, permit number: JLU2014-0303.

\section{Availability of data and materials}

All the data supporting the conclusions of this article is available and included within the article and its additional files.

\section{Additional files}

Additional file 1: Table S3. The Accession Numbers of OMPs of Brucella spp. in NCBI Protein database. (DOC $32 \mathrm{~kb}$ )

Additional file 2: Fig S1. IELISA assay analysis of serum samples in negative controls, healthy individuals and patients with other bacterial infection. (DOC $1403 \mathrm{~kb}$ )

Additional file 3: Table S2. Isotype specific reactivity positive results from the sera of brucellosis patients(146 samples) and controls(102 samples) in ELISA. (DOC $30 \mathrm{~kb})$

Additional file 4: Table S1. Specimen characteristics of positive and negative. (DOC $30 \mathrm{~kb}$ )

\section{Abbreviations}

ELISA: Enzyme-linked immunosorbent assay; ROC: Receiver-operating characteristic; CDC: Chinese center for disease control and prevention; PCR: Polymerase chain reaction; OMPs: Outer membrane proteins; NCBI: National center for biotechnology information; LB: Luria-Bertani; OD: Optical density; NTA: Ni-nitrilotriacetic acid; PAT: Plate agglutination test; SAT: standard tube agglutination test; PVDF: Polyvinylidene fluoride; RT: Room temperature; PTG: Isopropyl- $\beta$-D-thiogalactoside; Cl: Confidence interval; rOmp: Recombinant outer membrane protein; HRP: Horseradish peroxidase; BSA: Bovine serum albumin; AUC: The area under the ROC curve.

\section{Competing interests}

The authors declare that they have no competing interests.

\section{Authors' contributions}

D-HY, LL, X-LS, JL, and KX conceived and designed the study. HL, X-FQ, X-JM, $\mathrm{H}-\mathrm{QC}$, and $\mathrm{W}-\mathrm{YS}$ collected brucellosis data. D-H Y, LL, D-DS, Y-SL, R-ZM, and J-H L performed the ELISA assay. D- $H Y$ and $L L$ analyzed the data. D-HY drafted the manuscript; J W and WJ provided constructive opinions and suggestions. JW, WJ, JL, and KX reviewed and made improvements in the manuscript. All authors read and approved the final version of the paper.

\section{Acknowledgments}

We thank all study participants, and Plague and Brucellosis Prevention and Control Base for their support.

\section{Funding}

This work was supported by the National Natural Science Foundation of China (Grant number 81401721, 81473018 and 81502849) and Graduate Innovation Fund of Jilin University(Grant number 2015089). The funders had no role in study design, data collection and analysis, decision to publish, or preparation of the manuscript.

\section{Author details}

'Department of Health Laboratory, School of Public Health, Jilin University, Changchun, China. ${ }^{2}$ Department of Infection Control, First Hospital of Jilin University, Changchun, China. ${ }^{3}$ Jilin Entry-Exit Inspection and Quarantine Bureau, Changchun, China.

Received: 20 August 2015 Accepted: 7 May 2016 Published online: 21 May 2016

\section{References}

1. Zygmunt MS, Diaz MA, Teixeira-Gomes AP, Cloeckaert A. Cloning, nucleotide sequence, and expression of the brucella melitensis sucb gene coding for an immunogenic dihydrolipoamide succinyltransferase homologous protein. Infect Immun. 2001;69:6537-40.

2. Cloeckaert A, Vizcaino N, Paquet JY, Bowden RA, Elzer PH. Major outer membrane proteins of Brucella spp.: Past, present and future. Vet Microbiol. 2002;90:229-47.

3. Pappas G, Papadimitriou P, Akritidis N, Christou L, Tsianos EV. The new global map of human brucellosis. Lancet Infect Dis. 2006;6:91-9.

4. Shang DQ, Xiao DL, Yin JM. Epidemiology and control of brucellosis in China. Vet Microbiol. 2002;90:165-82.

5. Wang Y, Zhang W, Ke Y, Zhen Q, Yuan X, Zou W, Li S, Sun Y, Wang Z, Wang D, Cui B, Song H, Huang L, Chen Z. Human brucellosis, a heterogeneously distributed, delayed, and misdiagnosed disease in china. Clin Infect Dis. 2013;56(5):750-1.

6. Mantur BG, Mangalgi SS. Evaluation of conventional Castaneda and lysis centrifugation blood culture techniques for diagnosis of human brucellosis. J Clin Microbiol. 2004:42:4327-28.

7. Ciocchini AE, Rey Serantes DA, Melli LJ, Iwashkiw JA, Deodato B, et al. Development and validation of a novel diagnostic test for human brucellosis using a glyco- engineered antigen coupled to magnetic beads. PLoS Negl Trop Dis. 2013;7(2):e2048.

8. Alikhani MY, Hashemi SH, Naseri Z, Farajnia S, Peeri-Dogaheh H, Hashemi SH. Diagnosis of Human Brucellosis by Blood Culture (BACTEC) and PCR Method via Whole Blood and Serum. Jundishapur J Microbiol. 2013;6(3): 248-51.

9. Almuneef $M$, Memish ZA. Prevalence of Brucella antibodies after acute brucellosis. J Chemother. 2003;15:148-51.

10. Ibañez AE, Smaldini P, Coria LM, Delpino MV, Pacífico LGG, Oliveira SC, et al. Unlipidated Outer Membrane Protein Omp16(U-Omp16) from Brucella spp. as Nasal Adjuvant Induces a Th1 Immune Response and Modulates the Th2 Allergic Response to Cow's Milk Proteins. PLoS One. 2013;8(7):e69438.

11. de Wergifosse P, Lintermans P, Limet JN, Cloeckaert A. Cloning and nucleotide sequence of the gene coding for the major 25-kilodalton outer membrane protein of Brucella abortus. J Bacteriol. 1995:177(7):1911-14.

12. Paquet JY, Diaz MA, Genevrois S, Grayon M, Verger JM, de Bolle X, et al. Molecular, antigenic, and functional analyses of Omp2b porin size variants of Brucella spp. J Bacteriol. 2001;183(16):4839-47.

13. Vizcaíno N, Cloeckaert A, Zygmunt MS, Dubray G. Cloning, nucleotide sequence, and expression of the Brucell a melitensis omp31 gene coding for an immunogenic major outer membrane protein. Infect Immun. 1996; 64(9):374451.

14. Qiu J, Wang W, Wu J, Zhang H, Wang Y, Qiao J, et al. Characterization of Periplasmic Protein BP26 Epitopes of Brucella melitensis Reacting with Murine Monoclonal and Sheep Antibodies. PLoS ONE. 2012;7(3), e34246.

15. Olsen SC, Stoffregen WS. Essential role of vaccines in brucellosis control and eradication programs for livestock. Expert Rev Vaccines. 2005;4:915-28.

16. Perkins SD, Smither SJ, Atkins HS. Towards a Brucella vaccine for humans. FEMS Microbiol Rev. 2010;34:379-94.

17. Parker JMR, Guo D, Hodges RS. New hydrophilicity scale derived from highperformance liquid chromatography peptide retention data: correlation of predicted surface residues with antigenicity and $x$-ray-derived accessible sites. Biochemistry. 1986;25:5425-32.

18. Emini EA, Hughes JV, Perlow DS, Boger J. Induction of hepatitis a virusneutralizing antibody by a virus-specific synthetic peptide. J Virol. 1985;55(3): 836-9.

19. Chou PY, Fasman GD. Prediction of the secondary structure of proteins from their amino acid sequence. Adv Enzymol Relat Areas Mol Biol. 1978;47: 45-148.

20. Karplus PA, Schulz GE. Prediction of chain flexibility in proteins. Naturwissenschaften. 1985:72(4):212-3.

21. Pirovano W, Heringa J. Protein secondary structure prediction. Methods Mol Biol. 2010:609:327-48.

22. Sweredoski MJ, Baldi P. COBEpro: a novel system for predicting continuous B-cell epitopes. Protein Engineering, Design and Selection. 2009;22(3):113-20

23. Larsen JE, Lund $\mathrm{O}$, Nielsen M. Improved method for predicting linear B-cell epitopes. Immunome Res. 2006;2:2.

24. Araj GF. Update on laboratory diagnosis of human brucellosis. Int J Antimicrob Agents. 2010;36 Suppl1:12-7. 
25. Araj GF, Lulu AR, Mustafa MY, Khateeb MI. Evaluation of ELISA in the diagnosis of acute and chronic brucellosis in human beings. J Hyg (London). 1986;97:457-69.

26. Swets JA. Measuring the accuracy of diagnostic systems. Science. 1988;240: 1285-93.

27. Peeridogaheh $\mathrm{H}$, Golmohammadi MG, Pourfarzi F. Evaluati on of ELISA and Brucellacapt tests for diagnosis of human Brucellosis. Iran J Microbiol. 2013:5(1):14-8.

28. Deqiu S, Donglou X, Jiming Y. Epidemiology and control of brucellosis in China. Vet Microbiol. 2002;90:165-82.

Submit your next manuscript to BioMed Central and we will help you at every step:

- We accept pre-submission inquiries

- Our selector tool helps you to find the most relevant journal

- We provide round the clock customer support

- Convenient online submission

- Thorough peer review

- Inclusion in PubMed and all major indexing services

- Maximum visibility for your research

Submit your manuscript at www.biomedcentral.com/submit
Biomed Central 